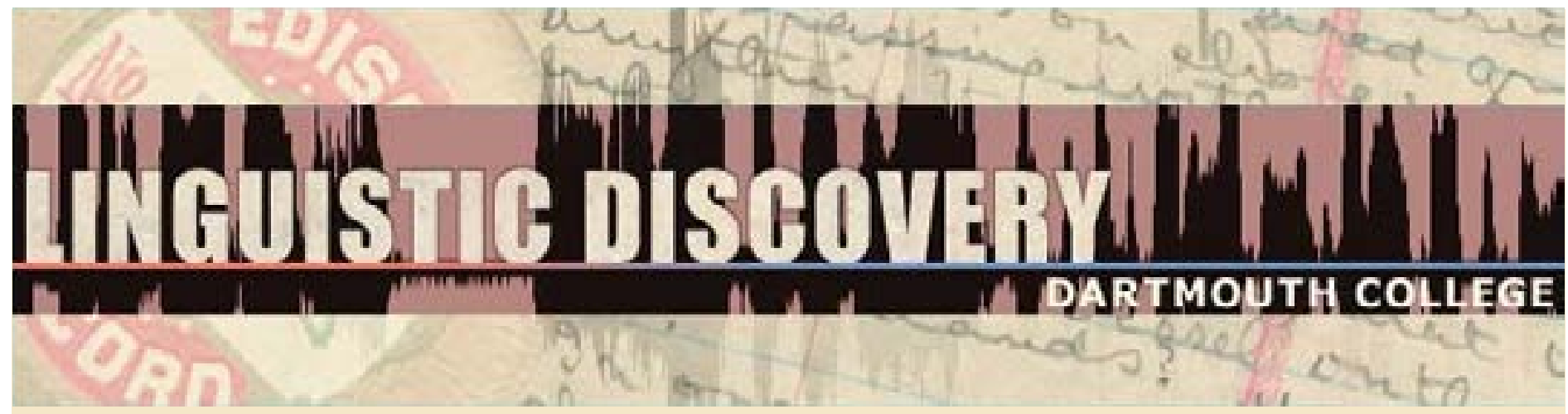

\begin{tabular}{|l|}
\hline Volume 8 \\
Issue 1 \\
2010 \\
\hline
\end{tabular}

\title{
Author's Reply - Getting to the Points of a Semantic Map
}

Joost Zwarts

Utrecht Institute of Linguistics OTS

doi: $10.1349 / P S 1.1537-0852 . A .384$

url: http://journals.dartmouth.edu/cgi-bin/WebObjects/ Journals.woa/1/xmlpage/1/article/384 


\title{
Getting to the Points of a Semantic Map
}

\section{Author's reply to 'A Multitude of Approaches to Make Semantic Maps' by Michael Cysouw (2010)}

\author{
Joost Zwarts \\ Utrecht Institute of Linguistics OTS
}

In his comment on my paper 'Semantic map geometry: two approaches', Michael Cysouw adds a few useful qualifications to the distinction that I made between matrix-driven and space-driven approaches to semantic maps. Even though there is a multitude of approaches, each of them with their individual advantages and disadvantages, I would like to maintain that the distinction that I made in my paper is valid and important.

I assume with Cysouw that the central question in the discussion is how to determine the relations between the points in a semantic space, not the points themselves, and I agree with him that this is a far-from-simple methodological distinction. In this debate, we share the assumption that points are somehow given. My discussion of space-based and matrix-based methods also deals with establishing the way a given set of "meanings" of some sort is structured by a relation between the points.

Cysouw does not see much coherence in the three candidate examples of space-driven mapping approaches that I mention in my paper, except that they are not based on crosslinguistic comparison. Of course, these three examples involve very different domains and methods, but the negative fact that they do not use cross-linguistic comparison to determine the relations between the meanings on the map implies something positive: they must establish those relations based on the properties of the points themselves (meanings, stimuli, denotations, image schemata), even though there are clearly different ways to do this, depending on the nature or modeling of the points.

Distinguishing between linguistic and non-linguistic methods for determining the relations between meanings might not be as easy as Cysouw makes it look, and it is partly a matter of terminology. Color space is determined on the basis of physical characteristics of color chips, the reciprocal lattice on the basis of logical properties of set-theoretic objects. The over network is really not very different: it is not determined by pure "linguistic" analysis, i.e. by comparing different lexical items or analyzing morphological or syntactic configurations, but by reflecting on the way different situations to which the preposition over can apply relate to each other, i.e. by "conceptual" analysis of those situations. This is no more or less linguistic than the way in which semanticists have studied the relations between different senses of each other using logical methods. Whether we call this linguistic or non-linguistic is of minor importance. What is important is that linguists who try to understand how lexical items and grammatical markers partition the world of meaning need to turn to non-linguistic facts, methods, and theories to understand how that world is structured: the physics of colors, the logic of relations, the conceptualization of spatial trajectories. There are two ways of doing this, both of which are part of linguistics, and both are needed: starting out with a hypothetical space (motivated by nonlinguistic considerations) and then investigate how languages in the world divide up this space, or work out a semantic map on the basis of cross-linguistic variation and then look for explanations of this map beyond the linguistic domain. 


\section{References}

Cysouw, Michael. 2010. A multitude of approaches to make semantic maps. Comment on Zwarts 2010. Linguistic Discovery, this issue.

Zwarts, Joost. 2010. Semantic map geometry: Two approaches. Linguistic Discovery, this issue.

Author's contact information:

Joost Zwarts

Opleiding Taalwetenschap

Departement Moderne Talen

Faculteit Geesteswetenschappen

Universiteit Utrecht

Trans 10

3512 JK Utrecht

The Netherlands

j.zwarts@uu.nl 